\title{
Friction and wear of HNBR with different fillers under dry rolling and sliding conditions
}

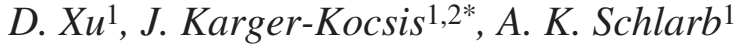 \\ ${ }^{1}$ Institut für Verbundwerkstoffe GmbH (Institute for Composite Materials), University of Kaiserslautern, \\ Erwin-Schrödinger-Str. 58, D-67663 Kaiserslautern, Germany \\ ${ }^{2}$ Department of Polymer Engineering, Faculty of Mechanical Engineering, Budapest University of Technology and \\ Economics, Múegyetem rkp. 3., H-1111 Budapest, Hungary
}

Received 15 November 2008; accepted in revised form 18 January 2009

\begin{abstract}
Peroxide cured hydrogenated acrylonitrile/butadiene rubber (HNBR) compounds with 20 parts per hundred rubber (phr) active fillers, such as carbon black (CB), multiwall carbon nanotube (MWCNT) and silica were produced and their friction and wear properties under unlubricated rolling and sliding conditions were evaluated. The network-related properties of the HNBR compounds were deduced from dynamic-mechanical thermal analysis (DMTA). The coefficient of friction $(\mathrm{COF})$ and the specific wear rate $\left(W_{s}\right)$ were determined in different home-made test rigs. The CB and MWCNT containing HNBR compounds exhibited the best resistance to rolling and sliding wear, respectively, among the HNBR systems studied. The worn surfaces were inspected in scanning electron microscope (SEM) and the wear mechanisms were analyzed and discussed in respect to the types of wear and fillers.
\end{abstract}

Keywords: rubber, reinforcement, $H N B R$, friction, wear

\section{Introduction}

Polymers are used in increasing amount in such technical parts where friction and wear properties are key factors. Wear resistant polymeric composites usually contain various fillers and reinforcements. Carbon black (CB), multiwall carbon nanotube (MWCNT) and silica are commonly used or considered as promising additives for rubbers to achieve high wear resistance.

$\mathrm{CB}$ is a 'preformed' nanofiller, composed of amorphous carbon, which has a high specific surface. It is mainly used as pigment and reinforcement in various rubber and plastic products. The abrasion wear properties of $\mathrm{CB}$ filled rubber products are excellent. However, the related products are black. When there is a special demand for colored products, silica $\left(\mathrm{SiO}_{2}\right)$ is often adopted to replace $\mathrm{CB}$.
By increasing the interaction between rubber matrices and silica, using different silanes, rubber compounds with very good abrasion resistance can be produced (e.g. [1]). Multiwall carbon nanotube (MWCNT) has high stiffness, strength and aspect ratio. MWCNT-containing polymer composites have outstanding mechanical performance, strongly improved electric and thermal conductivities if the nanotubes are well dispersed (for which, in analogy with organoclays, the term exfoliated is also used) and well adhered to the matrix [2]. A large body of research works addressed already the use of CB, silica and MWCNT in wear resistant polymer systems [1, 3-13], however, only few of them were dealt with hydrogenated acrylonitrile/ butadiene rubber (HNBR) [14-16]. 
In our previous paper [17], MWCNT and silica were introduced in 10 and 30 parts per hundred rubber (phr) into a peroxide-cured HNBR in order to enhance the resistance to both sliding and rolling wear. In the present work, the three kinds of fillers (CB, MWCNT and silica; $20 \mathrm{phr}$ for each) were added in the HNBR and their effects on the dry rolling and sliding wear against steel were checked and compared to those of the unfilled HNBR. Note that this filler amount is quite low for rubber recipes. However, when MWCNT is added in more than $20 \mathrm{phr}$ it is undergoing considerable attrition and breakage. Further, though the above fillers are different in their chemical build-up and physical structure, their tribological functions can still be compared because all of them are active (i.e. improving the stiffness and strength characteristics) rubber fillers. The rolling and sliding friction and wear properties were determined in orbital rolling ball (steel)-on-plate (rubber) (Orbital-RBOP), pin (steel)-on-plate (rubber) (POP), roller (steel)-onplate (rubber) (ROP) and oscillating cylinder (steel) on plate (rubber) (fretting) test rigs. Dynamicmechanical thermal analysis (DMTA) was used to deduce apparent network-related characteristics. The coefficient of friction (COF) and specific wear rate $\left(W_{s}\right)$ were determined for each tribotest. The worn surfaces were inspected in scanning electron microscope (SEM) and the wear mechanisms were concluded and discussed as a function of both wear and filler types.

\section{Experimental}

\subsection{Materials}

The composition of the peroxide curable HNBR was as follows: HNBR (Therban ${ }^{\circledR}$ LT VP/KA 8882 of Lanxess, Leverkusen, Germany; acrylonitrile content: $21 \%$, Mooney viscosity $\mathrm{ML}(1+4)$ at $\left.100^{\circ} \mathrm{C}=74\right)-100$ part, diphenylamine-based thermostabilizer (Luvomaxx CDPA of Lehmann \& Voss, Hamburg, Germany) - 1.1 part, zinc-containing mercapto-benzimidazole compound (Vulcanox $^{\circledR}$ ZMB 2/C5 of Lanxess) - 0.4 part, di(tertbutylperoxyisopropyl) benzene (Perkadox 14-40 B-PD of Akzo-Nobel, Düren, Germany; active peroxide content: $40 \%$ ) -7.5 part, $\mathrm{MgO}-2$ part, triallyl isocyanurate -1.5 part, $\mathrm{ZnO}-2$ part. Note that the amount of the listed additives corresponds to their phr content in the recipe. This mix of practical use was produced separately and provided by Lanxess. The curing time of this base mix to reach $90 \%$ crosslinking was ca. $10 \mathrm{~min}$ at $T=175^{\circ} \mathrm{C}$. This peroxide curable HNBR was mixed with 20 phr CB (N550), unmodified MWCNT (Baytubes ${ }^{\circledR}$ C 150 P from Bayer MaterialScience, Leverkusen, Germany) and silica (Ultrasil ${ }^{\circledR} \mathrm{VN} 2$ of Degussa, Frankfurt, Germany), respectively, on a two-roll mixing mill (LRM-150BE of Labtech, Bangkok, Thailand) at ca. $40^{\circ} \mathrm{C}$ by setting a friction ratio of 1.15.

Curing of the CB, MWCNT and silica filled HNBR to about $2 \mathrm{~mm}$ thick sheets $\left(100 \times 100 \mathrm{~mm}^{2}\right.$ surface $)$ occurred at $T=175^{\circ} \mathrm{C}$ for $15 \mathrm{~min}$ in a laboratory press. Specimens for the investigations listed below were cut from these sheets.

The samples prepared are referred to as HNBRPURE, HNBR-20CB, HNBR-20MWCNT and HNBR-20ULTRASIL, respectively, in the text. The digits in the designations represent the content of fillers in phr.

\subsection{Testing}

\subsubsection{Dynamic-mechanical thermal analysis (DMTA)}

DMTA spectra were recorded on rectangular specimens (length / $40 \mathrm{~mm} / \times$ width $/ 10 \mathrm{~mm} / \times$ thickness) in tensile mode with a superimposed sinusoidal $0.01 \%$ strain at a static preload $0.01 \mathrm{~N}$. The frequency was $10 \mathrm{~Hz}$ and the spectra were measured in a temperature range from -100 to $+100^{\circ} \mathrm{C}$ using a Q800 device of TA Instruments (New Castle, DE, USA). From $-100^{\circ} \mathrm{C}$, the temperature was increased by $5^{\circ} \mathrm{C}$ per step and for each step the temperature was stabilized for $3 \mathrm{~min}$.

\subsubsection{Density determination}

For the density determination the Archimedes principle (buoyancy method with water) was adopted according to the standard ISO 1183.

\subsubsection{Shore A hardness}

The Shore A hardness of the composites was measured according to ISO 868 using a hardness measuring device of Zwick (Ulm, Germany). 


\subsubsection{Rolling and sliding wear}

\section{Testing}

To evaluate the rolling friction and wear of the composites, an orbital rolling ball (steel)-on-plate (rubber) (Orbital-RBOP) home-made test rig was used. In the rig, the rubber sheet was worn by a steel ball (100Cr6, diameter: $14 \mathrm{~mm}$, arithmetical roughness $R_{a}: 1 \mu \mathrm{m}$ ), which rolled along a circular path (diameter: $33 \mathrm{~mm}$ ) being pushed by a defined normal load against the rubber sheet. The parameters set for this configuration were: normal load: $90 \mathrm{~N}$, revolution: $280 \mathrm{rpm}$, duration: 3 hours (h). This device allowed us to record the $\mathrm{COF}$ as a function of time.

Sliding friction and wear characteristics were determined in pin (steel)-on-plate (rubber) (POP), roller (steel)-on-plate (rubber) (ROP) and oscillating cylinder (steel) on plate (rubber) (fretting) tribotests.

POP is mounted in a Wazau device (Berlin, Germany), where a steel pin (100Cr6; arithmetical roughness, $R_{a}$, less than $1 \mu \mathrm{m}$ ) with a hemispherical head (diameter: $10 \mathrm{~mm}$ ) rotated along a circular path (diameter: $33 \mathrm{~mm}$ ). The pin was pushed against the rubber plate with a given load. The following parameters were selected for this configuration - normal load: $2 \mathrm{~N}$, sliding speed: $250 \mathrm{~mm} / \mathrm{s}$, duration: $1.5 \mathrm{~h}$. Measuring both the normal and the friction force components via a torque load cell allowed to calculate the COF and its monitoring during the tests.

In $\mathrm{ROP}$, a rotating steel roller $(9 \mathrm{SMnPb} 28 \mathrm{k}$, diameter: $10 \mathrm{~mm}$, width: $\left.20 \mathrm{~mm}, R_{a} \approx 0.9 \mu \mathrm{m}\right)$ was pressed against a rubber strip of $8-9 \mathrm{~mm}$ width in a SOP 3000 tribotester (Dr Tillwich GmbH, HorbAhldorf, Germany). The friction force induced by the torque was measured online and thus also the COF was recorded during the test. The test parameters were load: $2 \mathrm{~N}$; sliding speed: $250 \mathrm{~mm} / \mathrm{s}$; duration: $1.5 \mathrm{~h}$.

In the third tribotest (fretting) a steel cylinder oscillated on the surface of the fixed rubber specimen. The cylinder was pushed by a defined normal load against the rubber. The diameter and the contact length of the cylinder $\left(R_{a} \approx 0.9 \mu \mathrm{m}\right)$ were 15 and $<12 \mathrm{~mm}$ (varied), respectively. The applied experimental parameters were: normal load: $10 \mathrm{~N}$, frequency of the oscillation: $10 \mathrm{~Hz}$, stroke: $<3 \mathrm{~mm}$ (varied), duration: $<3 \mathrm{~h}$ (varied).
The specific wear rate was calculated according to Equation (1):

$$
W_{s}=\frac{\Delta V}{F \cdot L}
$$

where $\Delta V\left[\mathrm{~mm}^{3}\right]$ is the volume loss, $F[\mathrm{~N}]$ is the normal load, $\mathrm{L}[\mathrm{m}]$ is the overall rolling/sliding distance. The loss volume $(\Delta V)$ was calculated by measuring the depth and width of the wear tracks by white light profilometer (see later).

The test set-up of the above testing methods is depicted schematically in Figure 1.

\section{Failure}

The worn surfaces were investigated in a MicroProf white light profilometer (Fries Research \& Technology, Bergisch Gladbach, Germany) and in SEM (JSM-6300 of Jeol, Tokyo, Japan and ZEISS Supra $^{\mathrm{TM}}$ 40VP, Oberkochen, Germany). The specimens were sputtered with an $\mathrm{Au} / \mathrm{Pd}$ alloy in a device of Balzers (Lichtenstein) prior to SEM investigation at high acceleration voltages.

\section{Results and discussion}

\subsection{Network-related properties and hardness}

Figure 2 demonstrates the measured storage modulus $\left(E^{\prime}\right)$ and loss factor $(\tan \delta)$ as a function of the temperature changing from -100 to $100^{\circ} \mathrm{C}$. The position of the glass transition temperature of the HNBR composites $\left(T_{g} \approx-25^{\circ} \mathrm{C}\right)$ was practically not affected by the incorporation and type of the fillers. One can get the impression that introducing fillers in HNBR increased the stiffness in the rubbery stage of the composites, where the MWCNT's effect is much stronger than $\mathrm{CB}$ and silica.

Based on the plateau modulus $\left(E_{p l}\right)$ at $T=25^{\circ} \mathrm{C}$ the apparent mean molecular mass between crosslinks $\left(M_{c}\right)$ and the network density $\left(v_{c}\right)$ can be calculated by considering the rubber elasticity theory (Equations (2) and (3)):

$$
\begin{aligned}
& M_{c}=\frac{3 \cdot \rho \cdot R \cdot T}{E_{p l}} \\
& v_{c}=\frac{\rho}{M_{c}}
\end{aligned}
$$



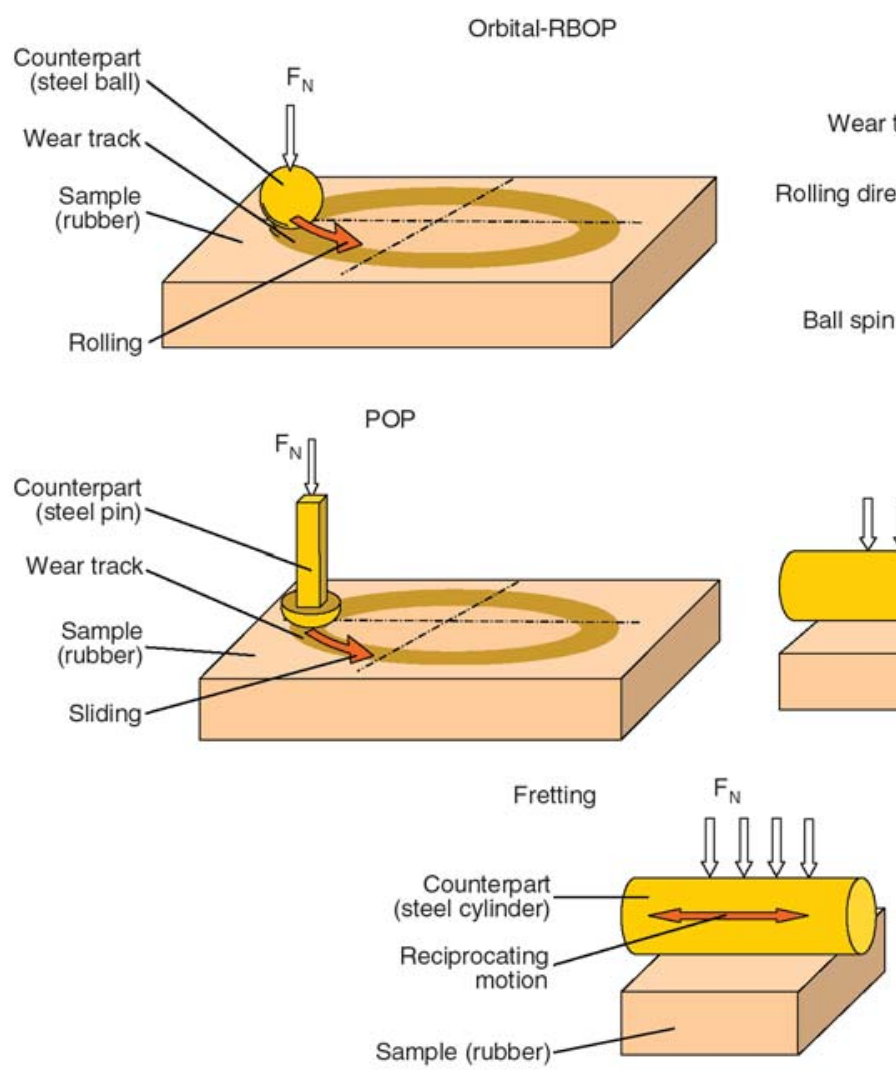

Figure 1. Schemes of the test configurations of Orbital-RBOP, POP, ROP and fretting. This figure also shows the preparation of the samples for SEM investigations after Orbital-RBOP test (top right)

Table 1. Basic network-related properties and hardness of the HNBR compounds studied

\begin{tabular}{|l|c|c|c|c|}
\hline & HNBR-PURE & HNBR-20CB & HNBR-20MWCNT & HNBR-20ULTRASIL \\
\hline$M_{c}[\mathrm{~g} / \mathrm{mol}]$ & 2013 & 1775 & 407 & 1437 \\
\hline$v_{c}\left[\mathrm{~mol} / \mathrm{dm}^{3}\right]$ & 0.52 & 0.61 & 2.7 & 0.76 \\
\hline $\tan \delta$ at $T_{g}$ & 1.37 & 1.25 & 0.68 & 1.02 \\
\hline Density $\left[\mathrm{g} / \mathrm{cm}^{3}\right]$ & 1.057 & 1.091 & 1.102 & 1.099 \\
\hline Shore $\mathrm{A}\left[{ }^{\circ}\right]$ & 42 & 54 & 75 & 56 \\
\hline
\end{tabular}

where $E_{p l}$ is the modulus at the absolute temperature of $298 \mathrm{~K}, \rho$ is the density, $R$ is the universal gas constant $(8.314 \mathrm{~J} /(\mathrm{K} \cdot \mathrm{mol}))$, and $T$ is the absolute temperature (i.e. $T=298 \mathrm{~K}$ ).

The apparent $M_{c}$ and $v_{c}$ values are listed in Table 1. It is noteworthy that HNBR-20MWCNT has the smallest $M_{c}$ and accordingly the highest $v_{c}$. This reflects that MWCNT had the strongest influence on the rubber-filler and filler-filler interactions and thus possesses the highest reinforcing efficiency (reflected in improved stiffness- and strengthrelated parameters) among the fillers used. This is likely due to its high aspect ratio and not to some chemical bonding to the rubber matrix.

The Shore A hardness increased when fillers were added in the HNBR. The ranking of the fillers in

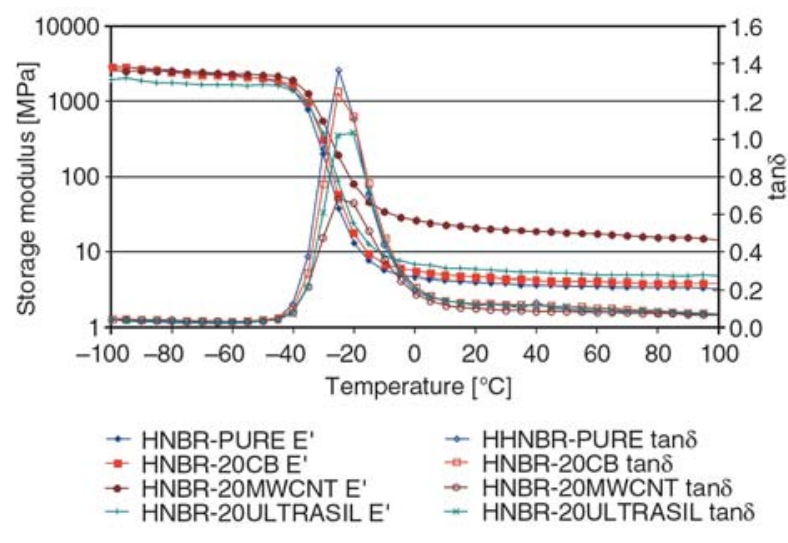

Figure 2. Storage modulus and loss factor $\tan \delta$ as a function of temperature for the HNBR studied

respect to the hardness enhancement was MWCNT $>$ Ultrasil ( silica) $>$ CB. 


\subsection{Friction and wear}

Figure 3 shows the COF and $W_{s}$ of HNBR with and without fillers measured in Orbital-RBOP (Figure 3a) and POP, ROP, fretting (Figures $3 b$ and c) tests. Results in Figure 3 a suggests that incorporation of $\mathrm{CB}, \mathrm{MWCNT}$ and silica lowered the $W_{s}$ and slightly enhanced the COF. CB proved to be better in improving the rolling wear resistance of HNBR compared to MWCNT and silica. The low scatter in the COF data under Orbital-RBOP is linked with the related wear mechanisms (see later).

The filled HNBR compounds have smaller $W_{s}$ in POP and ROP but do not perform better in fretting than HNBR-PURE (cf. Figure 3b). The authors have no explanation for the latter observation. It is noteworthy that the $W_{s}$ of HNBR-20MWCNT is
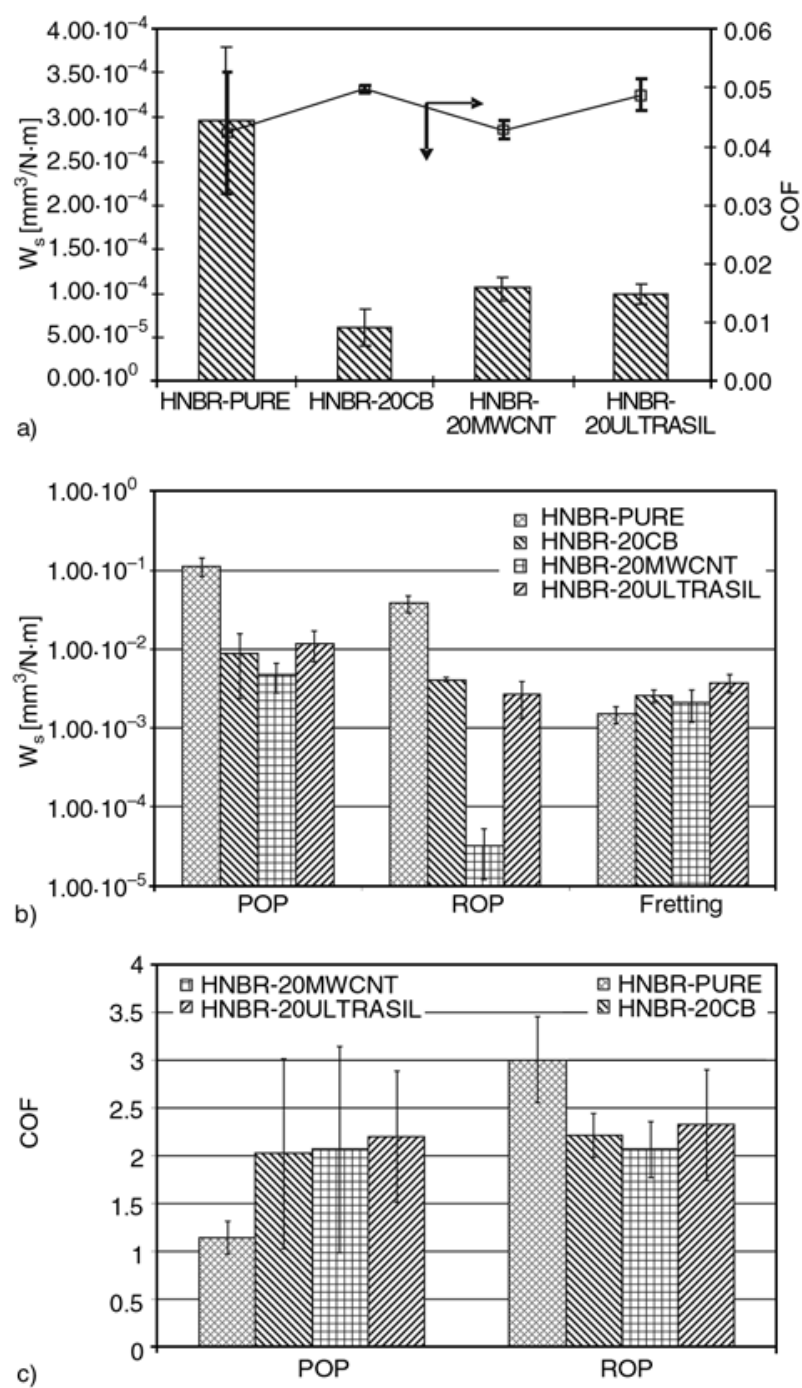

Figure 3. a - $W_{s}$ (column) and COF (line) after OrbitalRBOP tests, $\mathrm{b}-W_{s}$ after POP, ROP and fretting tests, c - steady-state COF after POP, ROP and fretting tests the smallest both under POP and ROP conditions compared to all other HNBR mixes.

Figure $3 \mathrm{c}$ shows the steady-state dynamic $\mathrm{COF}$ for POP and ROP tests. There are no COF data for fretting because the fretting rig was not able to record COF higher than 1.5. Filled HNBR systems have higher COF than pure HNBR in POP. However, the incorporation of fillers decreased the COF compared to HNBR-PURE under ROP testing. SEM photos reason this phenomenon very well (as shown later). The MWCNT-containing HNBR has the smallest COF compared to HNBR-20CB and -20ULTRASIL in ROP test. It is noteworthy that the above ranking reflects the tendency in the $\mathrm{COF}$, which is underlying to considerable scatter.

It is notable that the best fillers among the used three in respect to rolling and sliding wear resistances are $\mathrm{CB}$ and MWCNT, respectively. For the rolling contact, the stress distribution can roughly be estimated by the Hertzian law [16]. As a deviation from the Hertzian law, the maximum stress is often lying beneath the surface and this is responsible for the deterioration and failure of the material (e.g. fatigue induced internal hole formation followed by material spalling). As sliding and rolling contacts are quite different the common reinforcements for rubbery materials to enhance the resistance to sliding wear may not be associated with a similar improvement for rolling wear.

\subsection{Failure during rolling and sliding wear}

A detailed analysis on the wear mechanisms of pure HNBR in rolling and sliding wear tests can be found in our previous paper [17]. For the sake of comparison selected SEM pictures on the worn surfaces of HNBR-PURE are still inserted in order to facilitate the understanding of the results by the readers.

\subsubsection{Rolling wear}

Figure 4 shows SEM pictures taken from the rolling wear track of HNBR-PURE. Since the movement of the ball in Orbital-RBOP is guided by a bearing ring, the ball has an additional circumferential rotation (spin). As a result, the wear track may show different features in various regions. This was the reason to divide the track into three regions - cf. Figure 1 [17]. Figures $4 \mathrm{a}$ and $4 \mathrm{c}$ show the worn surfaces of the regions with additional for- 


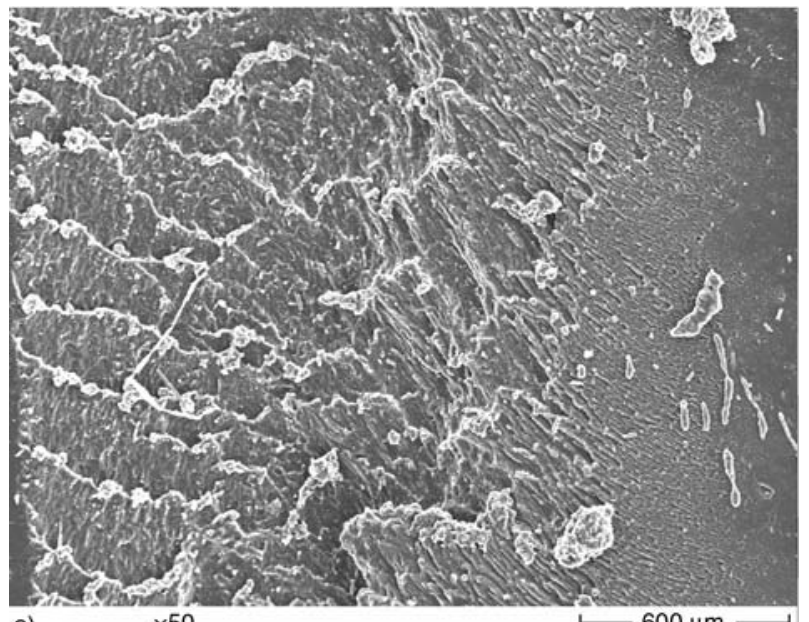

a)

$\times 50$

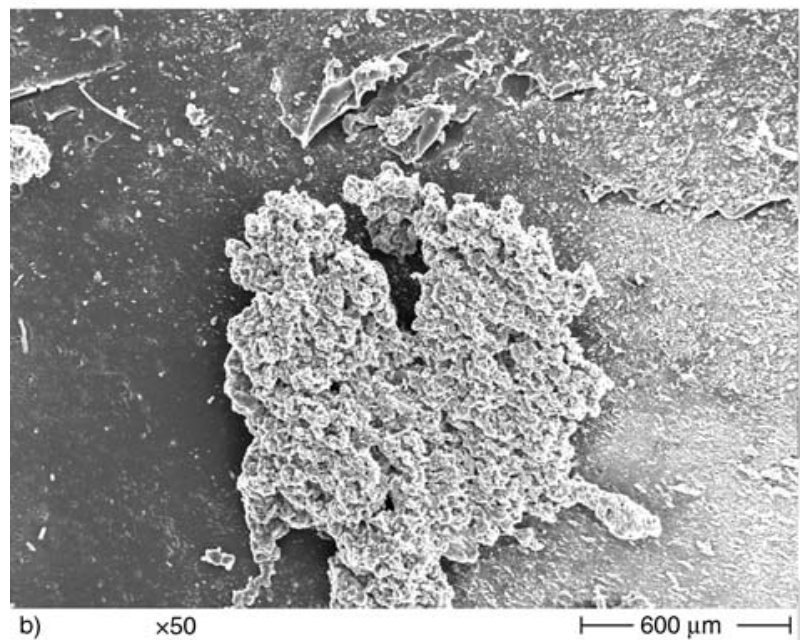

b)

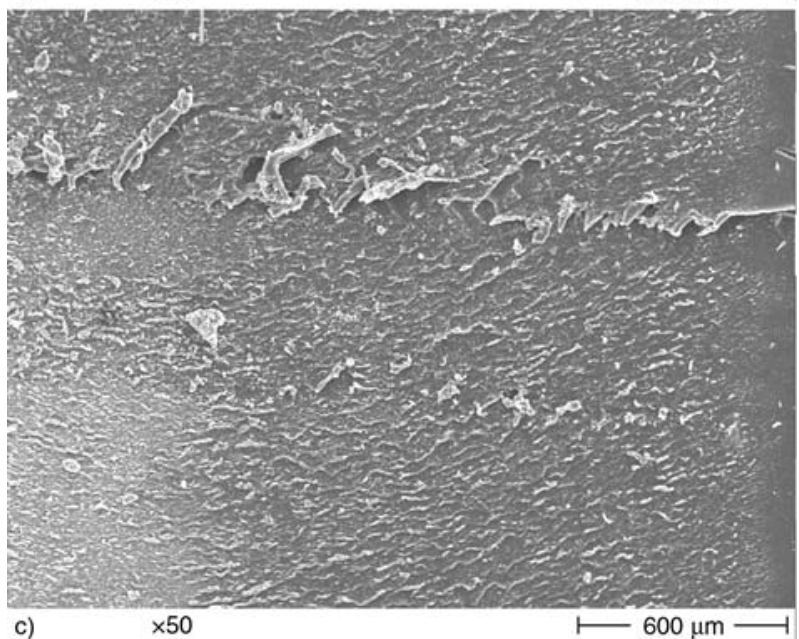

Figure 4. SEM photos taken from the rolling wear track of HNBR-PURE after Orbital-RBOP test. a - outer region, $\mathrm{b}$ - centre region, $\mathrm{c}-$ inner region. Note: rolling direction is downward.

ward (outer region - cf. Figure 1) and backward spins of the ball (inner region - cf. Figure 1), respectively. Figure $4 \mathrm{~b}$ is the region between the outer and inner regions (centre region - cf. Figure 1).
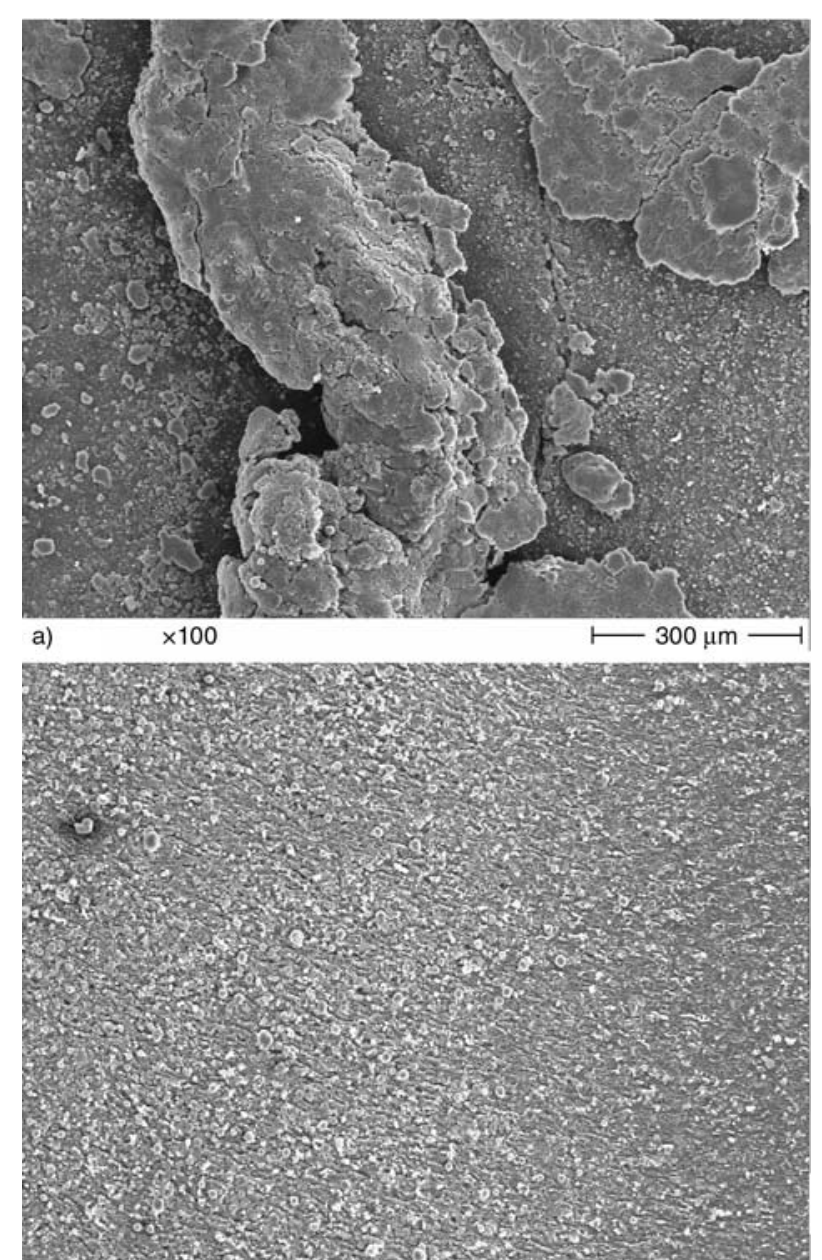

b)

$\times 100$

$\longmapsto 300 \mu \mathrm{m}$

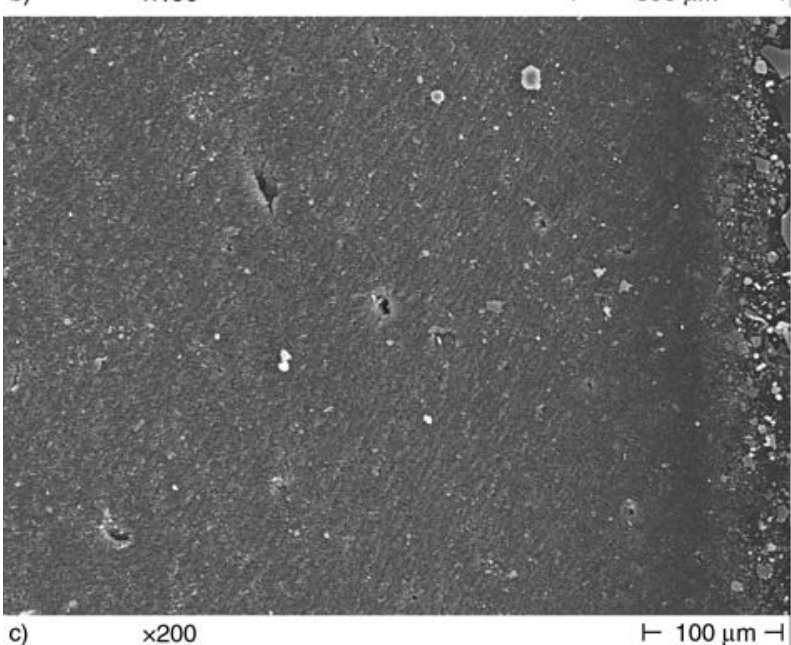

Figure 5. SEM photos taken from the rolling wear track of HNBR-20CB after Orbital-RBOP test. a - outer region, $\mathrm{b}$ - centre region, $\mathrm{c}-$ inner region. Note: rolling direction is downward.

Unlike HNBR-PURE (cf. Figure 4), the worn surface of the outer region of HNBR-20CB did not show surface waves, called Schallamach-type pattern, which results from elastic instability caused by the tangential force in the contact region 
between the rubber and the steel counterpart (cf. Figure 4a) [18]. The introduction of CB may account for the disappearance of the waves, as often observed in rubbery systems with active fillers [3, 5 and 19]. Instead, large agglomerates appeared in the outer region (cf. Figure 5a). Frag-
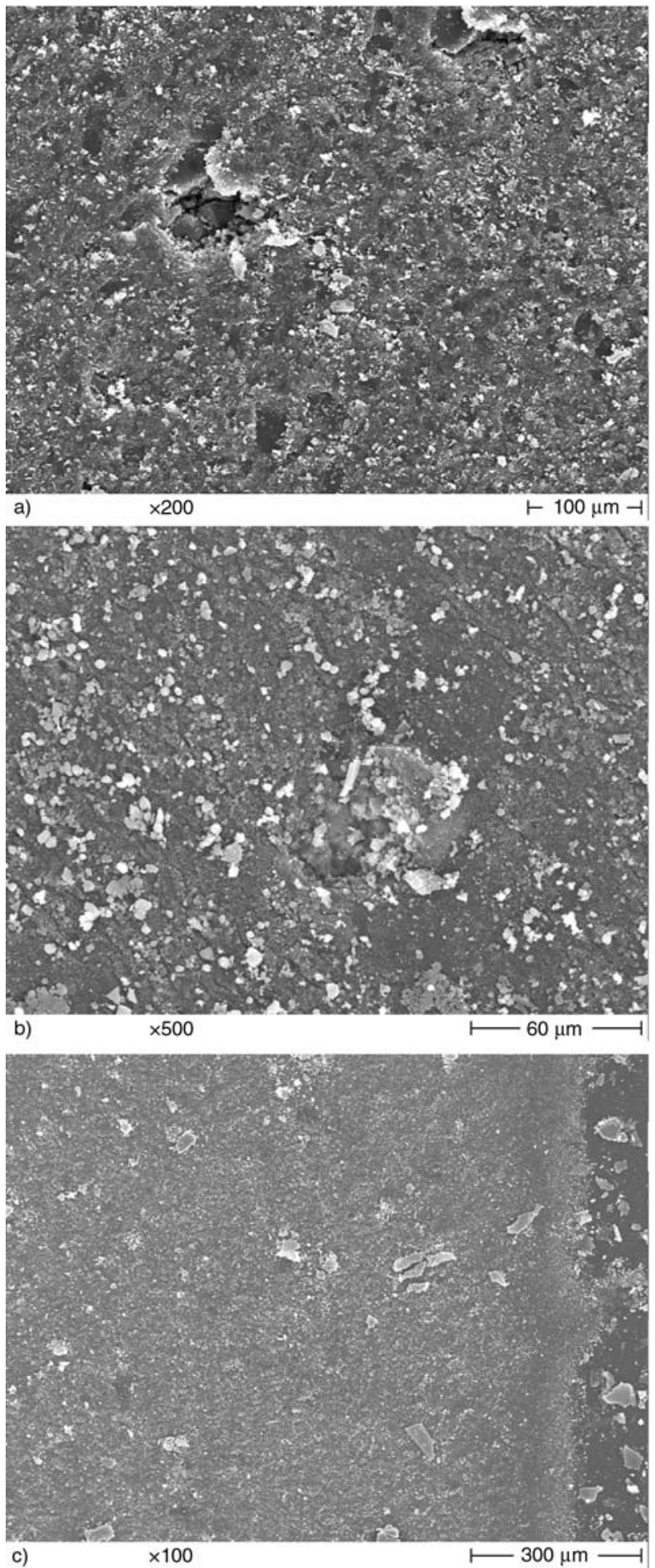

Figure 6. SEM photos taken from the rolling wear track of HNBR-20MWCNT after Orbital-RBOP test. $\mathrm{a}$ - outer region, $\mathrm{b}$ - centre region, $\mathrm{c}$ - inner region. Note: rolling direction is downward. mentation of debris is the wear characteristic in the centre region (cf. Figure 5b). Fatigue induced hole formation can be found in the inner region of the wear track (cf. Figure 5c). Recall that their onset is owing to spalling events.
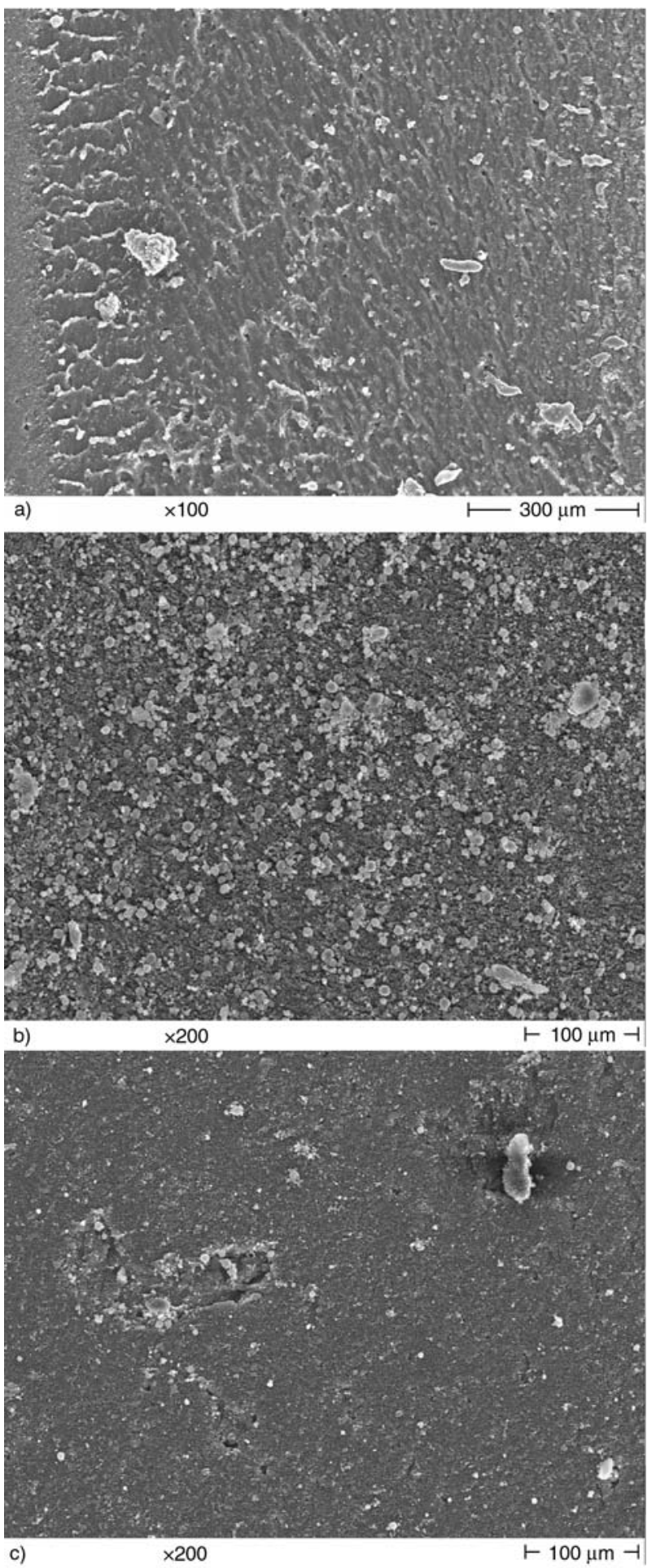

Figure 7. SEM photos taken from the rolling wear track of HNBR-20ULTRASIL after Orbital-RBOP test. $\mathrm{a}$ - outer region, $\mathrm{b}$ - centre region, $\mathrm{c}$ - inner region. Note: rolling direction is downward. 
Figure 6 collects SEM photos taken from the three regions of the wear track of MWCNT reinforced HNBR. Fatigue induced-spalling and fragmentation are the main wear mechanisms in the outer and centre regions (cf. Figures $6 a$ and $6 b$ ). In the inner region, flattened debris scatter over the whole area (cf. Figure 6c).

Figure 7 displays the worn surface of HNBR20ULTRASIL. In the outer region, Schallamach pattern with roll head, flat particles and agglomerates are discernible (cf. Figure 7a). Fragmentation is the main wear mechanism in the centre region (cf. Figure 7b). 'Ironed' particles and holes due to fatigue can be observed in the inner region of the worn surface (cf. Figure 7c).

By reviewing Figures 4-7, it is noticable that the Schallamach-type pattern disappeared completely or the area of its onset narrowed when the HNBR was filled. This change in the wear mechanisms is in line with the reduced specific wear rate observed for the filled HNBR mixes (cf. Figure 3a). The
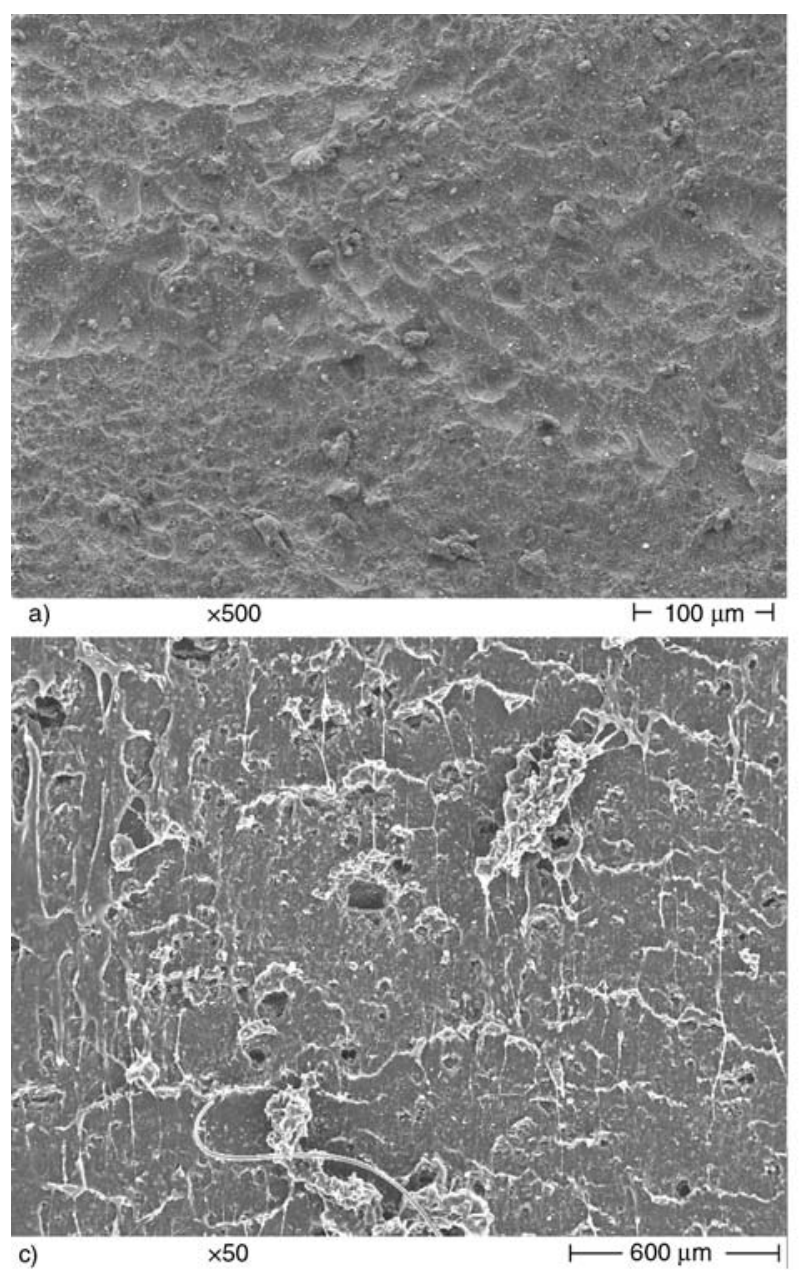

debris and fragmented surface in the center region of the wear track of filler containing compounds result likely in higher COFs compared to HNBRPURE.

\subsubsection{Sliding wear}

Figure 8 shows SEM photos of the worn surfaces of the HNBR compounds after POP tests. HNBR20CB and -20ULTRASIL show abrasion type pattern with fragments (cf. Figures $8 \mathrm{~b}$ and $8 \mathrm{~d}$ ). Note that they have very similar $W_{s}$ and COF values (cf. Figures $3 b$ and $3 c$ ). This suggests that the $C B$ and ULTRASIL have similar reinforcing effects in the HNBR. By contrast, HNBR-PURE failed by crater formation (to show this phenomenon a high magnification SEM picture has been selected). When MWCNT was added in HNBR, rolled debris, holes and an elongated fibrillar structure appeared which dominated the whole worn surface (cf. Figure 8c).
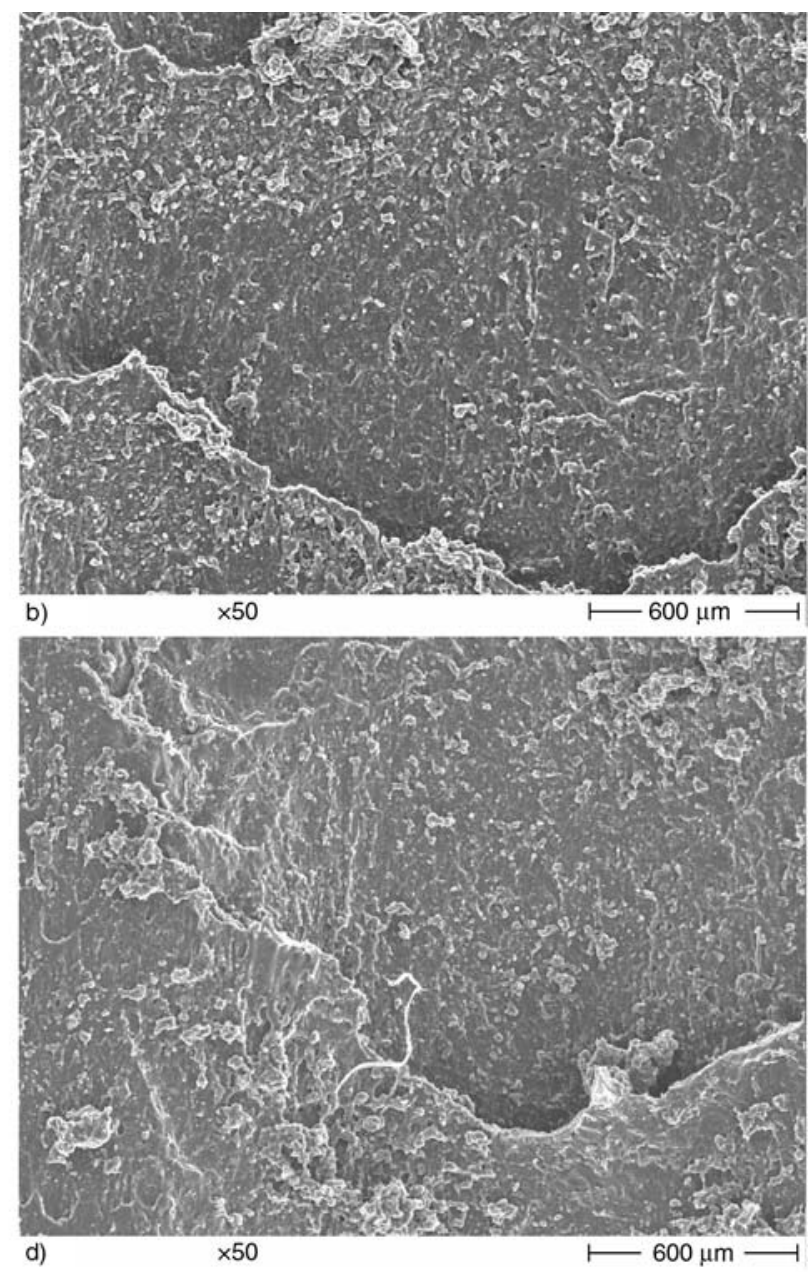

Figure 8. SEM photos taken from the worn surfaces of HNBR-PURE (a), -20CB (b), -20MWCNT (c) and -20ULTRASIL (d) after POP tests. Note: sliding direction is downward. 

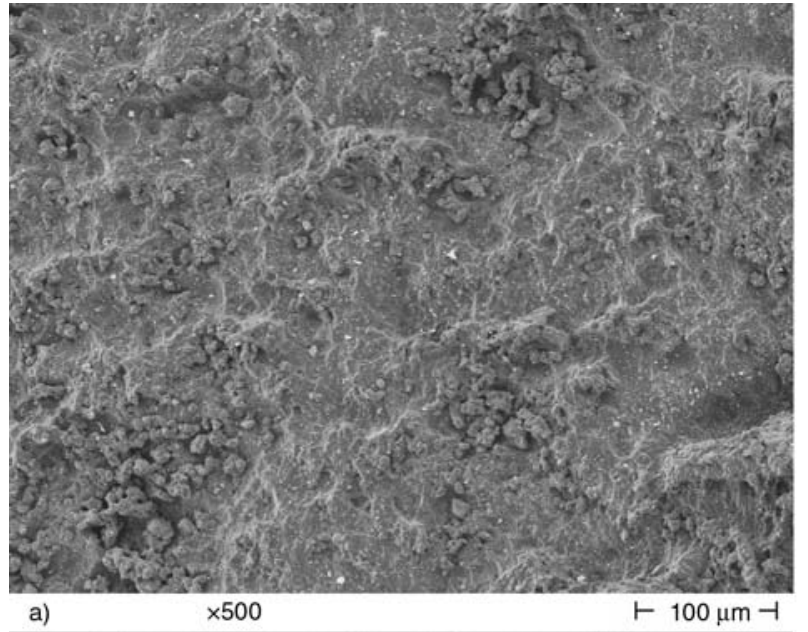

$\times 500$

$\vdash 100 \mu \mathrm{m} \dashv$

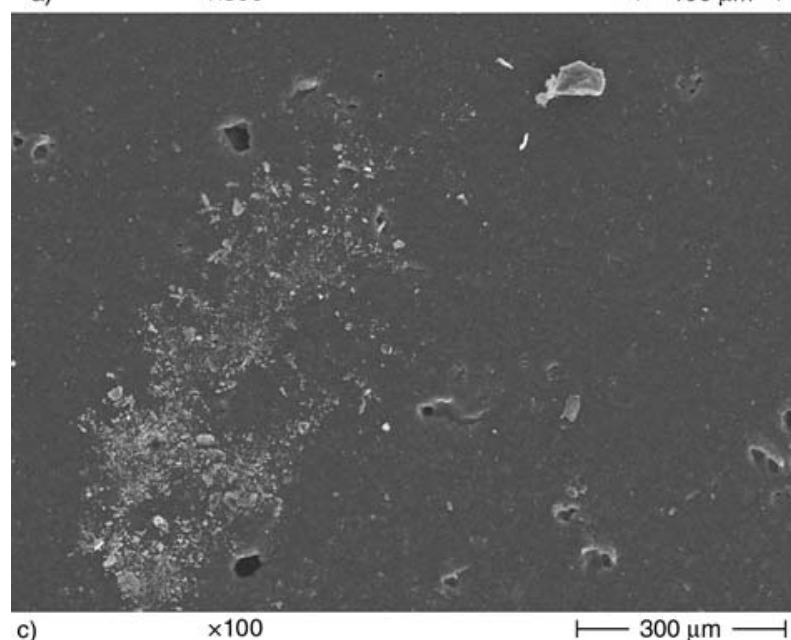

c)

$\times 100$

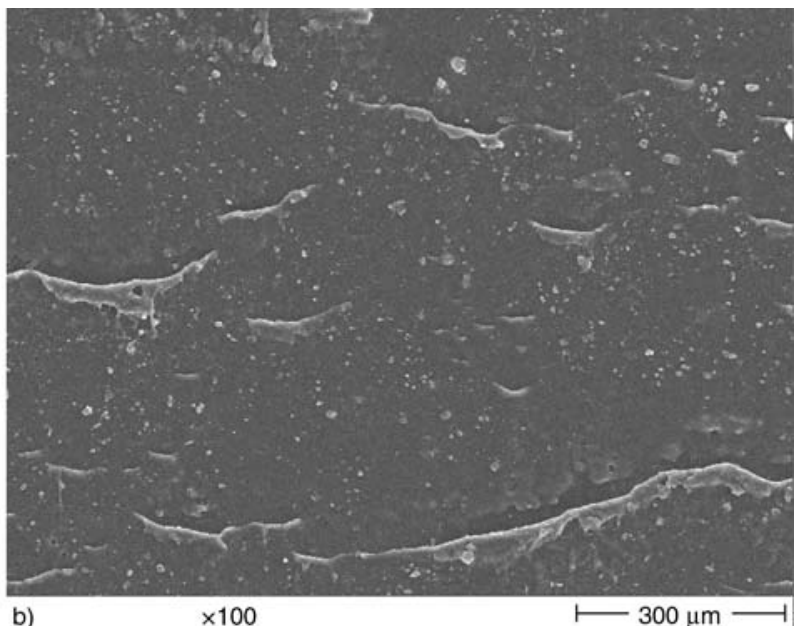

b)

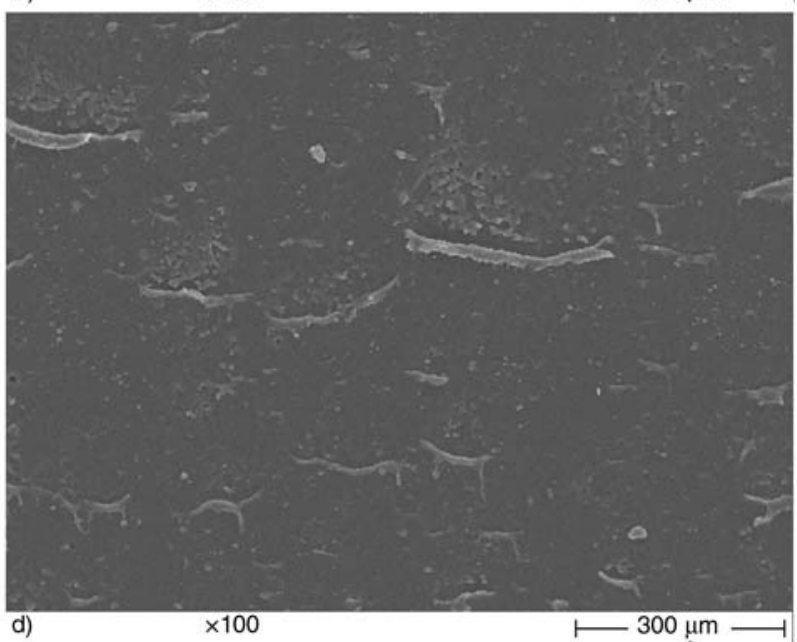

d)

$\vdash 300 \mu \mathrm{m}$

Figure 9. SEM photos taken from the worn surfaces of HNBR-PURE (a), -20CB (b), -20MWCNT (c) and -20ULTRASIL

(d) after ROP tests. Note: sliding direction is downward.

The worn surfaces of HNBR without and with active fillers (CB, MWCNT and silica) after ROP tests are displayed in Figure 9. CB and silica reinforcements of HNBR produce similar worn surfaces, where slightly extended and 'ironed' rolling stripes can be observed (cf. Figures $9 \mathrm{~b}$ and $9 \mathrm{~d}$ ). This similarity in the wear mechanisms is reflected in similar $W_{s}$ and COF data of HNBR-20CB and -20ULTRASIL in ROP. The failure scenario is different for HNBR-20MWCNT (cf. Figure 9c) in which small particles and holes are found on the ROP worn surface .This may hint for some reorganization of the MWCNT at the interface under ROP conditions. However, this speculative explanation has to be checked by further testing.

In fretting tests, peeling is the common predominant wear mechanism for all three filled HNBR compounds (cf. Figure 10). However, HNBR20MWCNT has some unique feature due to hole formation in the peeling-type wear track (cf. Fig- ure 10c). HNBR-PURE fails by crating also under fretting (cf. Figure 10a).

Like for rolling wear, the change of the wear mechanisms is in line with the observed changes in the specific wear rates. Note that similar wear mechanisms result in similar wear losses, i.e. the related $W_{s}$ values are well matched. The higher (POP) and lower (ROP) COFs of the filled HNBRs is most likely due to the rougher (POP) and smoother (ROP) surfaces produced.

\section{Conclusions}

HNBR compounds with $20 \mathrm{phr}$ various active fillers (CB, MWCNT and silica) was investigated by different rolling and sliding wear testing configurations under dry condition. The network-related apparent characteristics of the HNBR compounds were deduced from DMTA measurements. The COF and $W_{s}$ were determined and the wear mecha- 


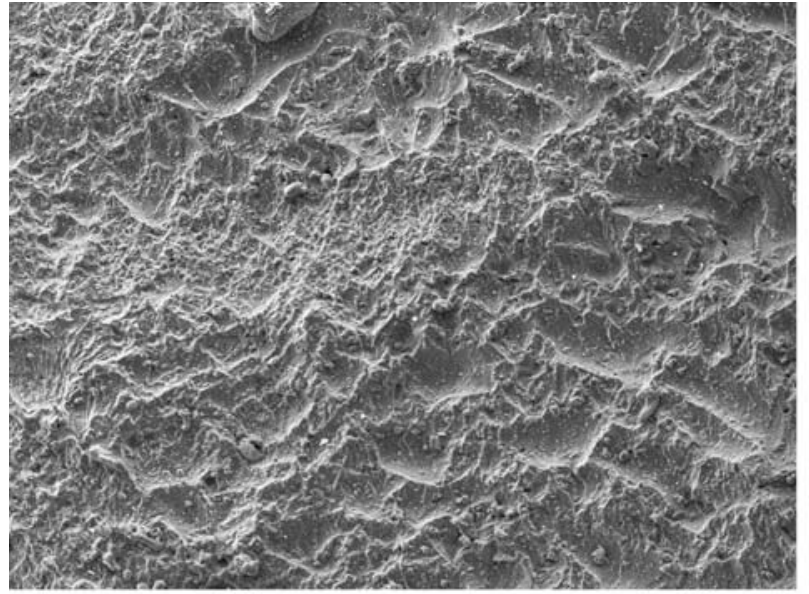

a)

$\times 500$

$\vdash 100 \mu \mathrm{m} \dashv$

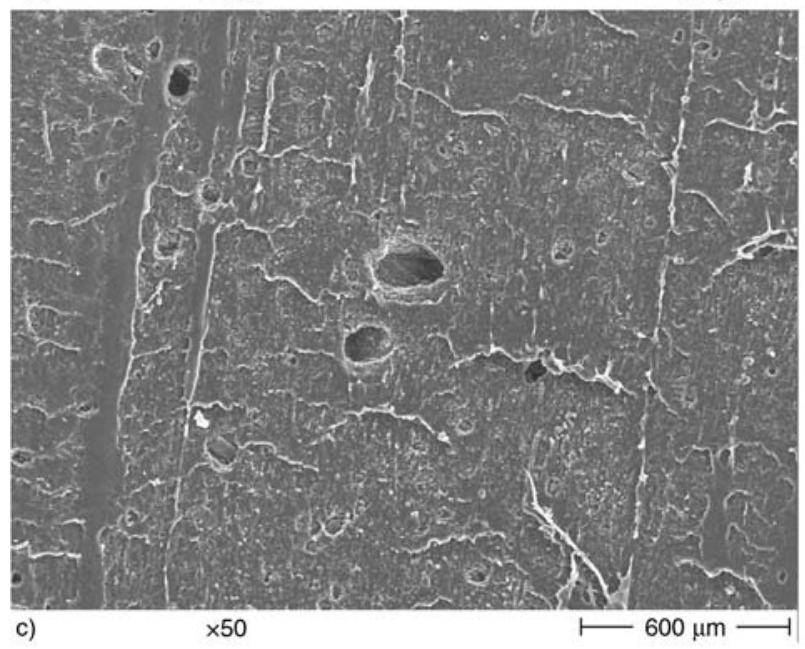

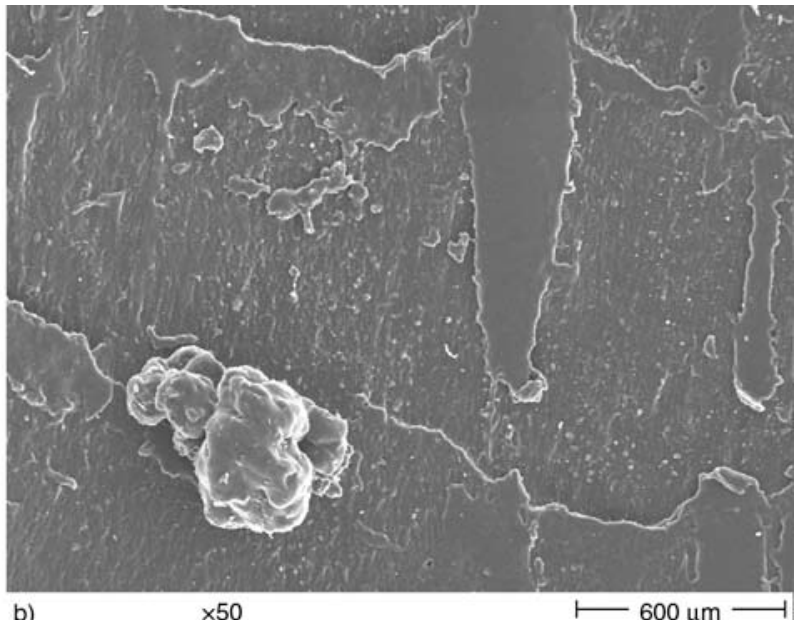

b)

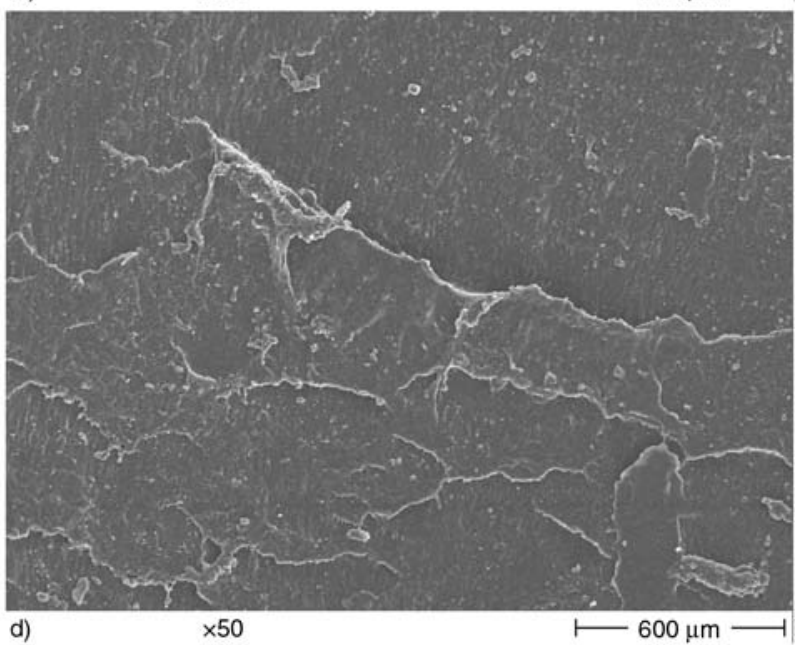

Figure 10. SEM photos taken from the worn surfaces of HNBR-PURE (a), -20CB (b), -20MWCNT (c) and -20ULTRASIL (d) after fretting tests. Note: sliding direction is vertical.

nisms under rolling and sliding conditions were identified. Results of this research work can be concluded as follow:

- MWCNT had the strongest reinforcing effect and thus the most pronounced influence on the rubber-filler and filler-filler interactions among the fillers used.

- CB- and MWCNT-containing HNBR compounds exhibited the best resistance to rolling and sliding wear, respectively. This was attributed to a difference in the stress distributions during rolling and sliding contacts causing pronounced changes in the wear mechanisms, which themselves depend on type and characteristics of the filler used.

- CB and silica have similar effects in respect to the sliding wear behavior (POP, ROP and fretting) when considering the corresponding $W_{s}$, COF data and wear mechanisms.
- Fatigue-induced hole formation is the unique characteristic for the sliding wear mechanisms of HNBR-20MWCNT. This may be linked with a weaker resistance of HNBR-20MWCNT to fatigue and with an eventual reorganization of the MWCNT at the sliding interface. This phenomenon, behind which MWCNT agglomeration is suspected, needs further investigation.

\section{Acknowledgements}

Ms. D. Xu thanks the DFG (German Research Foundation) for her fellowship (Graduate school GK 814). Part of this work was done in the framework of the EU project 'Kristal' (Contract Nr.: NMP3-CT-2005-515837; www.kristal-project.org). The support of Mr. H. Giertzsch in the SEM work is gratefully acknowledged. The HNBR mix was kindly supplied by Dr. M. Mezger (Lanxess, Leverkusen, Germany). 


\section{References}

[1] Wang M. J.: Effect of filler-elastomer interaction on tire tread performance part III. Kautschuk Gummi Kunststoffe, 61, 159-165 (2008).

[2] Xiong J., Zheng Z., Qin X., Li M., Li H., Wang X.: The thermal and mechanical properties of a polyurethane/multi-walled carbon nanotube composite. Carbon, 44, 2701-2707 (2006). DOI: $10.1016 /$ j.carbon.2006.04.005

[3] Xu D., Karger-Kocsis J., Schlarb A. K.: Rolling wear of EPDM and SBR rubbers as a function of carbon black contents: Correlation with microhardness. Journal of Materials Science, 43, 4330-4339 (2008). DOI: $10.1007 / \mathrm{s} 10853-008-2637-7$

[4] Nayek S., Bhowmick A. K., Pal S. K., Chandra A. K.: Wear behavior of silica filled tire tread compounds by various rock surfaces. Rubber Chemistry and Technology, 78, 705-723 (2005).

[5] Karger-Kocsis J., Mousa A., Major Z., Békési N.: Dry friction and sliding wear of EPDM rubbers against steel as a function of carbon black content. Wear, 264, 357-365 (2008).

DOI: 10.1016/j.wear.2007.03.021

[6] Choi S-S., Park B-H., Song H.: Influence of filler type and content on properties of styrene-butadiene rubber (SBR) compound reinforced with carbon black or silica. Polymers for Advanced Technologies, 15, 122127 (2004)

DOI: $10.1002 /$ pat.421

[7] Wei Z., Zhao Y-P., Ruan S. L., Gao P., Yu T. X.: A study of the tribological behavior of carbon-nanotubereinforced ultrahigh molecular weight polyethylene composites. Surface and Interface Analysis, 38, 883886 (2006).

DOI: $\underline{10.1002 / \mathrm{sia} .2148}$

[8] Chen H. Y., Jacobs O., Wu W., Rudiger G., Schädel B.: Effect of dispersion method on tribological properties of carbon nanotube reinforced epoxy resin composites. Polymer Testing, 26, 351-360 (2007). DOI: $10.1016 /$ j.polymertesting.2006.11.004

[9] Enomoto K., Yasuhara T., Kitakata S., Murakami H., Ohtake N.: Frictional properties of carbon nanofiber reinforced polymer matrix composites. New Diamond and Frontier Carbon Technology, 14, 11-20 (2004).
[10] Wang C., Dong B., Gao G-Y., Xu M-W., Li H-L.: A study on microhardness and tribological behavior of carbon nanotubes reinforced AMMA-CNTs copolymer nanocomposites. Materials Science and Engineering: A, 478, 314-318 (2008).

DOI: $10.1016 /$ j.msea.2007.06.036

[11] Chen W. X., Li F., Han G., Xia J. B., Wang L. Y., Tu J. P., Xu Z. D.: Tribological behavior of carbon-nanotube-filled PTFE composites. Tribology Letters, $\mathbf{1 5}$, 275-278 (2003). DOI: $10.1023 / \mathrm{A}: 1024869305259$

[12] Du J. H., Bai J., Cheng H. M.: The present status and key problems of carbon nanotube based polymer composites. Express Polymer Letters, 1, 253-273 (2007). DOI: $10.3144 /$ expresspolymlett.2007.39

[13] Song H-J., Zhang Z-Z., Men X-H.: Surface-modified carbon nanotubes and the effect of their addition on the tribological behavior of a polyurethane coating. European Polymer Journal, 43, 4092-4102 (2007). DOI: $\underline{10.1016 / j . e u r p o l y m j .2007 .07 .003}$

[14] Thavamani P., Bhowmick A. K.: Abrasion of swollen rubber vulcanizates. Plastics Rubber and Composites Processing and Applications, 18, 35-45 (1992).

[15] Thavamani P., Bhowmick A. K.: Influence of compositional variables and testing temperature on the wear of hydrogenated nitrile rubber. Journal of Materials Science, 28, 1351-1359 (1993). DOI: $10.1007 / \mathrm{BF} 01191977$

[16] Sarkar A. D.: Friction and wear. Academic Press, London (1980).

[17] Felhős D., Karger-Kocsis J., Xu D.: Tribological testing of peroxide cured HNBR with different MWCNT and silica contents under dry sliding and rolling conditions against steel. Journal of Applied Polymer Science, 108, 2840-2851 (2008).

DOI: 10.1002/app.27624

[18] Schallamach A.: How does rubber slide? Wear, 17, 301-312 (1971).

[19] Felhős D., Karger-Kocsis J.: Tribological testing of peroxide-cured EPDM rubbers with different carbon black contents under dry sliding conditions against steel. Tribology International, 41, 404-415 (2008). DOI: $\underline{10.1016 / \text { j.triboint.2007.09.005 }}$ 